Tropical Journal of Pharmaceutical Research May 2015; 14(5): 761-768

ISSN: $1596-5996$ (print); 1596-9827 (electronic)

(C) Pharmacotherapy Group, Faculty of Pharmacy, University of Benin, Benin City, 300001 Nigeria.

All rights reserved.

Available online at http://www.tjpr.org

Original Research Article

http://dx.doi.org/10.4314/tjpr.v14i5.3

\title{
Optimization of a Novel Oral Colon Delivery System of Indomethacin Using Full Factorial Design
}

\author{
Samar A Afifi ${ }^{1,2}$, Walaa M Mandour ${ }^{1}$ and Kadria A Elkhodairy ${ }^{1,3 *}$ \\ ${ }^{1}$ Department of Pharmaceutics, College of Pharmacy, King Saud University, Riyadh, Saudi Arabia, ${ }^{2}$ Department of \\ Pharmaceutics, National Organization for Drug Control and Research, Giza, ${ }^{3}$ Department of Industrial Pharmacy, Faculty of \\ Pharmacy, Alexandria University, Alexandria, Egypt
}

*For correspondence: Email: elkhodairy53@yahoo.com; Tel: 00966543791270; Fax: 0096612913735

Received: 9 January 2015

Revised accepted: 12 April 2015

\begin{abstract}
Purpose: To develop and optimize indomethacin (IDM) matrix tablets for specific colon drug delivery. Methods: Indomethacin matrix tablets containing hydrogenated castor oil (HCO), and pectin (PEC) were prepared by hot fusion method. $A 3^{2}$ full factorial design was used to investigate the combined effect of two independent formulation variables, X1 and X2, namely, the amount of HCO and PEC, respectively. Their effect on IDM release from the matrix tablets in acidic medium $(0.1 \mathrm{~N} \mathrm{HCl})$ and phosphate buffer ( $\mathrm{pH}$ 6.8), were analyzed and optimized. A contour plot was also applied to graphically represent the effect of the independent variables on drug release in pH 6.8 medium at $2 h(Y 1)$ and $24 h$ (Y2), and the time required for $25 \%$ drug release (Y3) as dependent variables.

Results: The optimized IDM matrix tablets showed almost total retardation of drug release in acidic medium and prolonged sustained release in $\mathrm{pH} 6.8$ medium over $24 \mathrm{~h}$. The correlation coefficient $\left(R^{2}\right)$ value for $Y 1, Y 2$ and $Y 3$ were $0.99850,0.9980$ and 0.9970 , respectively, indicating good correlation between dependent and independent variables. Differences between the coefficients for Y1, Y2 and Y3 were significant $(p<0.05)$, and hence contributed significantly to the prediction of the independent variables.

Conclusion: The findings indicate that successful design, development, and optimization of IDM matrix tablets for colon delivery has been achieved.
\end{abstract}

Keywords: Indomethacin, Hydrogenated castor oil, Pectin, Factorial design, Matrix tablets, Colon delivery system

Tropical Journal of Pharmaceutical Research is indexed by Science Citation Index (SciSearch), Scopus, International Pharmaceutical Abstract, Chemical Abstracts, Embase, Index Copernicus, EBSCO, African Index Medicus, JournalSeek, Journal Citation Reports/Science Edition, Directory of Open Access Journals (DOAJ), African Journal Online, Bioline International, Open-J-Gate and Pharmacy Abstracts

\section{INTRODUCTION}

Oral colon-specific drug delivery system (CDDS) has been developed as one of the site-specific drug delivery systems. This delivery system comprises a combination of one or more controlled release mechanisms leading to hardly any release of the drug in the upper part of the gastrointestinal $(\mathrm{Gl})$ tract, but rapid release in the colon following oral administration [1-3].
Polysaccharides are widely used in oral drug delivery systems because of the simplicity to obtain the desired drug delivery system and drug release profile, by the control of cross-linking, insolubility of crosslinked beads in gastric environment and broad regulatory acceptance [4-6]. The inability of the GIT enzymes to digest certain plant polysaccharides is taken advantage in developing a colon-specific drug delivery system. Various polysaccharides are being evaluated for colon targeting such as pectin 
(PEC), guar gum, gum ghatti, dextran, chitosan, and xylan $[7,8]$.

Indomethacin (IDM) is a nonsteroidal antiinflammatory drug (NSAID) that can exhibit chemoprotective effects against tumors and reduce the risk of colon cancer [9-11]. Despite recent advances in NSAIDs formulations, the design of targeted delivery systems to improve the efficacy and reduce side effects of NSAIDs continues to be a focus of much research [1214].

This study was aimed at the design and development of controlled release matrix tablets of IDM using hydrogenated castor oil ( $\mathrm{HCO})$ and PEC, with the aid of $3^{2}$ full factorial design, to achieve a colon targeted $24 \mathrm{~h}$ release profile in vitro.

\section{EXPERIMENTAL}

\section{Materials}

Indomethacin ( $\gamma$ - polymorphic form) (IDM) was kindly supplied by Pharco Pharmaceuticals, Alexandria, Egypt. Also used were pectin (PEC, $\mathrm{BDH}$ Co, England). hydrogenated castor oil (HCO, Girnar Industries, Gujarat, India, as well as talc and magnesium stearate (BDH Chemicals Ltd, Poole, UK). All other chemicals used were of reagent grade.

\section{Fourier transform infrared spectroscopy}

Fourier transform infrared (FTIR) spectrum of IDM and physical mixtures (1:1:1) of IDM with other excipients (PEC and $\mathrm{HCO}$ ) as well as different formulations prepared by hot fusion method, namely F4 and F6, were performed to find out any possible drug- excipients interaction using $\mathrm{KBr}$ pellet method using Perkin-Elmer FTIR series (model- 1615) spectrophotometer between $4000-450 \mathrm{~cm}^{-1}$.

\section{Preparation of indomethacin solid dispersions by hot fusion method}

Hydrogenated castor oil was melted in porcelain evaporating dish using a water bath at $60{ }^{\circ} \mathrm{C}$. Indomethacin and pectin were mechanically mixed to form homogenous mixture and then this mixture was added with continuous stirring (HCO, PEC and the drug were used in the required ratios for each preparation) to get a homogeneous dispersion. The obtained molten mass was then allowed to cool down and solidify. Subsequently, the mass was ground, pulverized and passed through a 60-mesh sieve $1<300$ $\mu \mathrm{m})$. The obtained powders were stored in desiccators at room temperature until use.

\section{Preparation of indomethacin matrix tablets}

The solid dispersion was directly compressed using a single punch tablet machine (Erweka, Germany) fitted with $9 \mathrm{~mm}$ diameter normal flat punches and die sets. Relatively constant tablet hardness was held around $10 \mathrm{~kg}$. An amount of solid dispersion equivalent to $50 \mathrm{mg}$ of IDM was compressed after the addition of $3 \% \mathrm{w} / \mathrm{w}$ (of tablet weight) of lubricant (Talc: Magnesium stearate 9:1). Tablet weight was $300 \pm 5 \mathrm{mg}$. Tablets were then subjected to in vitro release study.

\section{In vitro release studies}

The in vitro release study of IDM tablets was performed using USP apparatus II (Erweka, Germany) fitted with paddle (50 rpm) at $37 \pm 0.5$ ${ }^{\circ} \mathrm{C}$ using $0.1 \mathrm{~N} \mathrm{HCl}(\mathrm{pH} 1.2,900 \mathrm{~mL})$ as a dissolution medium for the first $2 \mathrm{~h}$, followed by $\mathrm{pH} 6.8$ phosphate buffer solutions for further 10 h. At the predetermined time intervals, $5 \mathrm{~mL}$ samples were withdrawn and replaced with fresh preheated dissolution medium, then the withdrawn samples were filtered through a 0.45 $\mu \mathrm{m}$ membrane filter and assayed spectrophometrically at $270 \mathrm{~nm}$ using a UV spectrophotometer (Shimadzu, Kyoto, Japan). Cumulative drug release was computed from a standard calibration curve. The dissolution profile of all batches were fitted to various models including zero order, first order [15], Higuchi [16, 17], Korsmeyer and Peppas [18] to ascertain the kinetics of drug release (Equations 1-4, respectively).

$\mathrm{C}=\mathrm{K}_{0} \mathrm{t}$

where, $\mathrm{K}_{0}$ is zero-order rate constant expressed in units of concentration/time and $t$ is the time.

$\log C=\log _{0}-K_{1} t / 2.303$

where $\mathrm{C}_{0}$ is the initial concentration of drug and $\mathrm{K}_{1}$ is first order constant.

$Q=K_{H} t^{1 / 2}$

where, $\mathrm{KH}$ is the constant reflecting the design variables of the system.

$\mathrm{M}_{\mathrm{t}} / \mathrm{M}_{\infty}=\mathrm{Kt}^{\mathrm{n}}$

where $M_{t} / M_{\infty}$ is fraction of drug released at time $t$, $\mathrm{K}$ is the release rate constant. 


\section{Optimization of variables using $3^{2}$ full factorial design}

A $3^{2}$ full factorial design was employed to systematically study the joint influence of the effect of independent variables $X_{1}$ and $X_{2}$ on the dependent variable. In this design, 2 factors were evaluated, each at 3 levels, and experimental trials were performed at all 9 possible combinations. The amounts of $\mathrm{HCO}\left(\mathrm{X}_{1}\right)$ and PEC $\left(X_{2}\right)$ were selected as independent variables in 32 full factorial design, while $Y 1, Y 2$ and $\mathrm{Y} 3$ (\% drug release after 2, $24 \mathrm{~h}$ and time required to release $25 \%$ drug, respectively) were taken as dependent variables. The formulation layout for the factorial design batches (F1-F9) is shown in Table 1.

\section{Response surface analysis}

Two dimensional (2-D) contour plot and three dimensional (3-D) surface response plots where constructed based on the model polynomial function using Minitab program version 17. These plots are very useful to see interaction effect on the factor of the response.

\section{Statistical analysis}

The results were analyzed by using Graph Pad software version 6 . One way analysis of variance (ANOVA) with Tukey's multiple comparisons post hoc was used to test for significant differences, and differences were considered significant at $p$ $<0.05$.

\section{RESULTS}

\section{Compatibility of IDM with the polymers}

Figure 1 demonstrates the characteristic IR peaks of pure IDM which were compared with peaks obtained from the respective physical mixture $(1: 1: 1)$ as well as with F4 and F6. It was observed that characteristic peaks of IDM appears with identical or with minor differences, at frequencies 3370.33 and $1717.14 \mathrm{~cm}^{-1}$ corresponding to carboxylic $\mathrm{O}-\mathrm{H}$ and $\mathrm{C}=\mathrm{O}$ stretch, respectively. The spectrum shows also characteristic peaks at $2961.65 \mathrm{~cm}^{-1}(\mathrm{C}-\mathrm{H}$ stretching vibrations), $\quad 1691.83 \mathrm{~cm}^{-1} \quad(\mathrm{C}=\mathrm{O}$ stretching vibrations), $1234.15 \mathrm{~cm}^{-1}$ (asymmetric aromatic O-C stretching), $\quad 1086.55 \mathrm{~cm}^{-1}$ (symmetric aromatic $\mathrm{O}-\mathrm{H}$ stretching) and $1479.50 \mathrm{~cm}^{-1}$ (C-C stretching) [19]. It can be seen that the peaks of the prepared formulations F4 and F6 as well as the physical mixture are the sum of the characteristic peaks of the drug and the corresponding excipients used. The spectra of Fig. 1 indicated the compatibility between the drug and the two polymers used for preparation of IDM matrix tablets by hot fusion technique.

\section{Preliminary trial}

In a preliminary study, batches containing various concentrations of $\mathrm{HCO}$ alone and in combination with the other polymer (PEC) were prepared to check their influence on in vitro characterization of compressed matrix tablets. It was found that as the concentration of $\mathrm{HCO}$ increased, the drug release for upper GIT was retarded till $6.79 \%$. It was found that tablets containing combinations of $\mathrm{HCO}$ with PEC retarded the drug release in $\mathrm{pH} 1.2$ and gave faster drug release in $\mathrm{pH} 6.8$.

\section{In vitro drug release}

Figure 2 illustrates the release profile of IDM from the different matrix tablets prepared by direct compression of the solid dispersion of the drug into the polymers.

Table 1: Composition and the experimental design of factorial design batches

\begin{tabular}{|c|c|c|c|c|c|}
\hline \multirow[t]{2}{*}{ Batch code } & \multicolumn{2}{|c|}{ Variable levels in coded form } & \multicolumn{3}{|c|}{ Dependent variables } \\
\hline & $\mathbf{X}_{1}$ & $\mathrm{X}_{2}$ & Y1 & Y2 & Y3 $\left(T_{25 \%}\right)$ \\
\hline $\mathrm{F} 1$ & -1 & -1 & 0.78 & 76.00 & 50.00 \\
\hline $\mathrm{F} 2$ & -1 & 0 & 0.98 & 66.20 & 47.32 \\
\hline F3 & -1 & +1 & 0.72 & 54.70 & 68.03 \\
\hline $\mathrm{F} 4$ & 0 & -1 & 1.20 & 70.00 & 39.60 \\
\hline F5 & 0 & 0 & 2.00 & 59.27 & 71.00 \\
\hline F7 & +1 & -1 & 0.30 & 67.54 & 79.00 \\
\hline F8 & +1 & 0 & 0.30 & 55.86 & 42.00 \\
\hline F9 & +1 & +1 & 0.00 & 41.43 & 40.00 \\
\hline
\end{tabular}

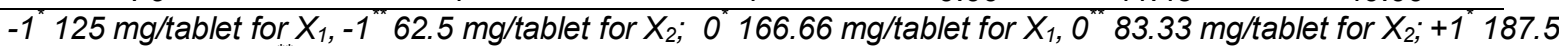
mg/tablet for $X_{1},+1^{* \star} 125$ mg/tablet for $X_{2}$ 


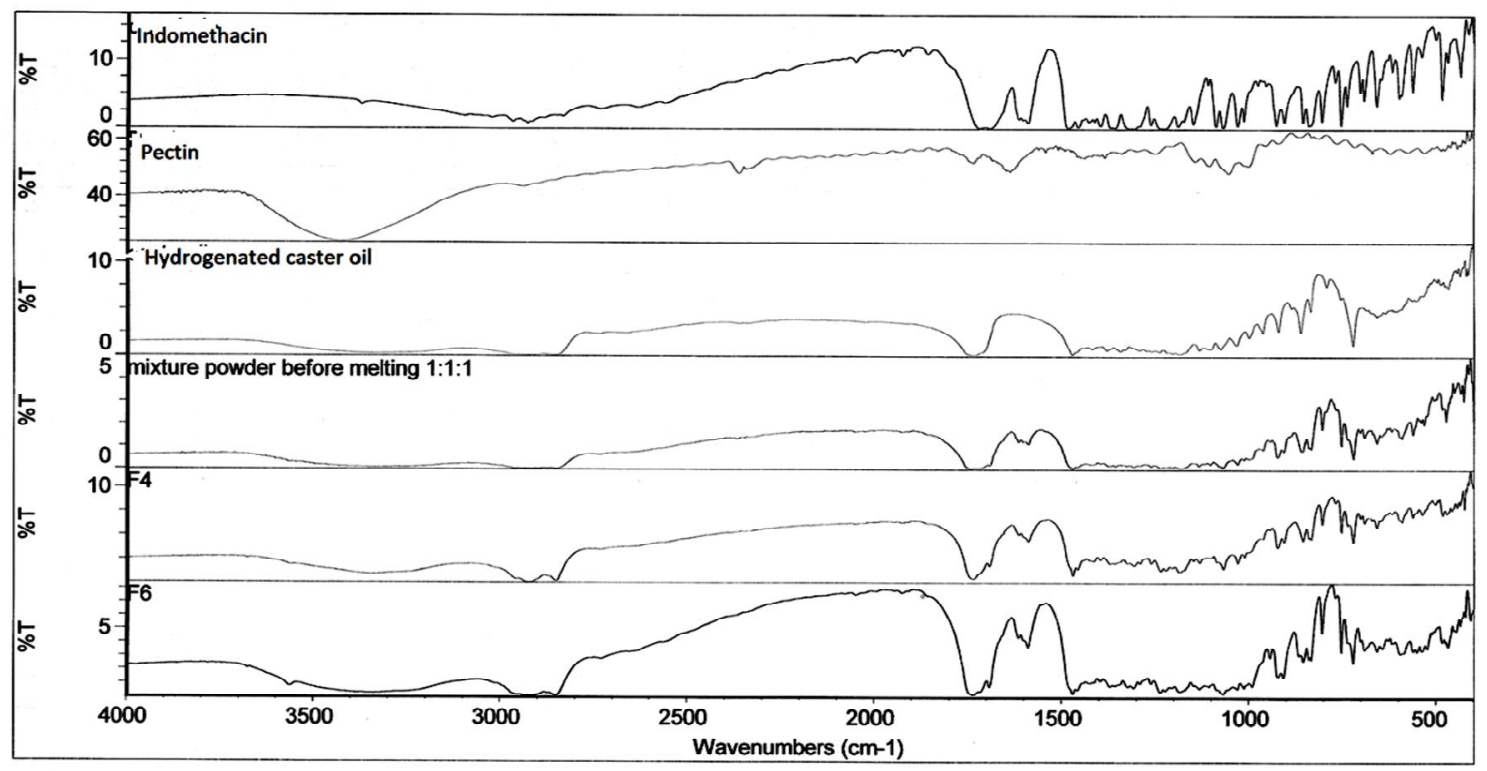

Figure 1: IR spectra of indomethacin, pectin, hydrogenated castor oil, their physical mixture in the ratio of 1:1:1 and after fusion (formulations F4 and F6)

The release profile of IDM from the 9 batches showed drug release in $\mathrm{pH} 6.8$ ranged from $0-2.5$ $\%$ after $2 \mathrm{~h}$ while, drug release after $24 \mathrm{~h}$ ranged from $41 \%$ to $76 \%$. The release of the drug after $24 \mathrm{~h}$ for all the tablets prepared was based upon the mechanical mixtures of IDM and pectin. However, tablets prepared using high concentration of HCO $(187.5 \mathrm{mg})$ showed IDM release of $<67 \%$ after $24 \mathrm{~h}$ whereas, the tablets prepared with medium (166.66 $\mathrm{mg}$ ) and low (125 $\mathrm{mg}$ ) concentrations of $\mathrm{HCO}$ released about 70 and $76 \%$ of the drug, respectively. As the amount of $\mathrm{HCO}$ increased from $125 \mathrm{mg}(\mathrm{F} 1, \mathrm{~F} 2$ and F3) to $187.5 \mathrm{mg}$ (F7, F8 and F9), the drug release was significantly decreased $(p<0.05)$. The in vitro release profiles of drug from all these formulations can be best expressed by Higuchi equation as the correlation coefficient $\left(R^{2}\right)$ values were the highest ( 0.820 for F4 to 0.923 for F5) as compared with the other release kinetic models studied.

\section{Full factorial design}

According to the $3^{2}$ factorial designs, various trial formulations of IDM matrix tablets were prepared by direct compression method using ingredients stated in Table 1. The results of the regression analysis indicated that these models were significant for all response parameters (Table 2). The minitab-17 program provided suitable polynomial model equations involving individual main factors and interaction factors after fitting these data.
A statistical model incorporating interactive and polynomial terms was used to evaluate the response.

$$
\begin{aligned}
& Y=b_{0}+b_{1} X_{1}+b_{2} X_{2}+b_{3} X_{1} X_{2}+b_{4} X_{1}^{2}+b_{5} X_{2}^{2}+ \\
& \left.b_{6} X_{1}^{2} X_{2}+b_{7} X_{1} X_{2}^{2}+b_{8} X_{1}^{2} X_{2}^{2} \ldots \ldots \ldots \ldots \ldots \ldots \ldots . .15\right)
\end{aligned}
$$

where, $Y$ is the dependent variable, $b_{0}$ is the intercept representing the arithmetic mean response of the nine runs, and $b_{1}$ is the estimated coefficient for the factor $X_{1}$. The main effects $\left(X_{1}\right.$ and $\left.X_{2}\right)$ represent the average result of changing one factor at a time from its low to high values. The interaction terms $\left(X_{1} X_{2}\right)$ show how the response changes when 2 factors are simultaneously changed. The polynomial terms $\left(\mathrm{X}_{1}^{2}\right.$ and $\left.\mathrm{X}_{2}^{2}\right)$ are included to investigate nonlinearity.

The data from Fig 2 and data of Table 1 indicate that the drug release profile is strongly dependent on the selected independent variables. The fitted equations relating the responses, $\mathrm{Y} 1, \mathrm{Y} 2$ and $\mathrm{Y} 3$ to the transformed factor are shown in Table 2.

The polynomial equations can be used to draw conclusions after considering the magnitude of coefficient and the mathematical sign it carries whether it is negative or positive. Table 2 shows the results of regression analysis which was performed to identify insignificant factors. Data were analyzed using Minitab 17 program. 

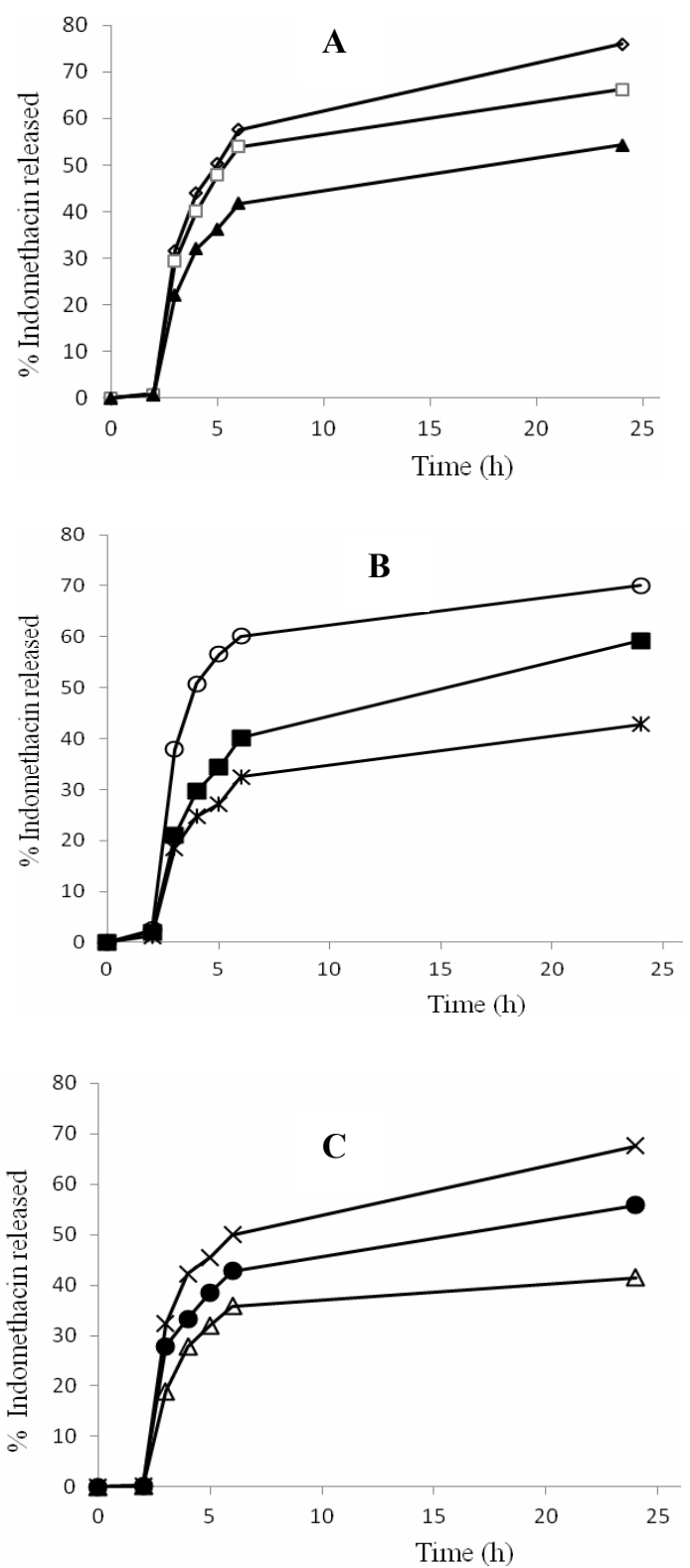

Fig 2: Release profiles of (A) IDM matrix tablets $\diamond F 1$, $\square \mathrm{F} 2$ and $\mathbf{\Delta} \mathrm{F} 3$; (B) IDM matrix tablets $\mathrm{OF} 4, \square \mathrm{F} 5$ and $*$ F6; (C) IDM matrix tablets $\times F 7, ~ O F 8$ and $\triangle F 9$. Test performed in $0.1 \mathrm{~N} \mathrm{HCl}$ for $2 \mathrm{~h}$ and thereafter in phosphate buffer ( $\mathrm{pH}$ 6.8)
$R^{2}$ value for $Y 1, Y 2$ and $Y 3$ are $0.99850,0.9980$ and 0.9970 , respectively, indicating good correlation between dependent and independent variables. The significance levels of the coefficients in the $Y 1, Y 2$ and $Y 3$ were found to be significant at $p<0.05$ hence contribute significance information to the prediction of the independent variables.

\section{Factorial equation for $\mathrm{Y} 1$}

$\mathrm{Y} 1=29.5992-0.84475 \mathrm{X}_{1}-13.0447 \mathrm{X}_{2}$

$+2.64943 X_{1} X_{2}+13.4493 X_{1}^{2}+8.1597 X_{2}^{2}$

$+11.6856 X_{1}^{2} X_{2}-2.67114 X_{1} X_{2}^{2}-$

$18.6842 \mathrm{X}_{1}^{2} \mathrm{X}_{2}^{2}$

\section{Factorial equation for $\mathrm{Y} 2$}

$Y 2=59.2694+0.67001 X_{1}-13.5987 X_{2}$

$+2.35862 X_{1} X_{2}+7.5979 X_{1}^{2}-2.8694 X_{2}^{2}$

$+5.31173 X_{1}^{2} X_{2}-8.38236 X_{1} X_{2}^{2}-6.3578 X_{1}^{2} X_{2}^{2}$ (7)

\section{Factorial equation for $\mathrm{Y} 3$}

$\mathrm{Y} 3=70.9987-2.65975 \mathrm{X}_{1}+20.6960 \mathrm{X}_{2}-$ $14.2558 X_{1} X_{2}-26.3390 X_{1}^{2}-10.7008 X_{2}^{2}-$ $25.9392 \mathrm{X}_{1}^{2} \mathrm{X}_{2}$

$+25.3029 X_{1}^{2} X_{2}^{2}$

(8)

\section{Response surface analysis}

Three-dimensional response surface plots and their corresponding contour plots to estimate the effects of the independent variables (factors) on each response investigated were presented in Fig. $3 \mathrm{~A}, \mathrm{~B}$ and $\mathrm{C}$. The three-dimensional response surface plots and corresponding contour plots relating drug release indicated the deceased values of $Y 1, Y 2$ and increased values of $Y 3$ with the increment of the two independent variables $X_{1}$ and $X_{2}$ (amounts of $\mathrm{HCO}$, and PEC in IDM matrix tablets).

Table 2: Results of regression analysis

\begin{tabular}{lrrrrrr}
\hline & \multicolumn{2}{c}{ Y1 } & \multicolumn{1}{c}{ Y2 } & \multicolumn{3}{c}{ Y3 } \\
\hline & Coefficient & P-value & Coefficient & P-value & Coefficient & $\boldsymbol{P}$-value \\
\hline Intercept & 29.5992 & 0.0001 & 59.2694 & 0.000 & 70.9987 & 0.000 \\
$\mathrm{X}_{1}$ & -0.84475 & 0.0002 & 0.67001 & 0.0001 & -2.65975 & 0.0003 \\
$\mathrm{X}_{2}$ & -13.0447 & 0.0001 & -13.5987 & 0.0003 & 20.6960 & 0.0001 \\
$\mathrm{X}_{1} \mathrm{X}_{2}$ & 2.64943 & 0.0001 & 2.35862 & 0.000 & -14.2558 & 0.0001 \\
$\mathrm{X}_{1}{ }^{2}$ & 13.4493 & 0.0002 & 7.5979 & 0.0001 & -26.3390 & 0.000 \\
$\mathrm{X}_{2}{ }^{2}$ & 8.1597 & 0.0001 & -2.8694 & 0.0003 & -10.7008 & 0.0002 \\
$\mathrm{X}_{1}{ }^{2} \mathrm{X}_{2}$ & 11.6856 & 0.0001 & 5.31173 & 0.0002 & -25.9392 & 0.0001 \\
$\mathrm{X}_{1} \mathrm{X}_{2}{ }^{2}$ & -2.67114 & 0.0001 & -8.38236 & 0.0001 & 2.89951 & 0.0001 \\
$\mathrm{X}_{1}{ }^{2} \mathrm{X}_{2}{ }^{2}$ & -18.6842 & 0.0001 & -6.3578 & 0.0001 & 25.3029 & 0.0001 \\
$\mathrm{R}^{2}$ & 0.99850 & & 0.9980 & & 0.997 & \\
\hline
\end{tabular}



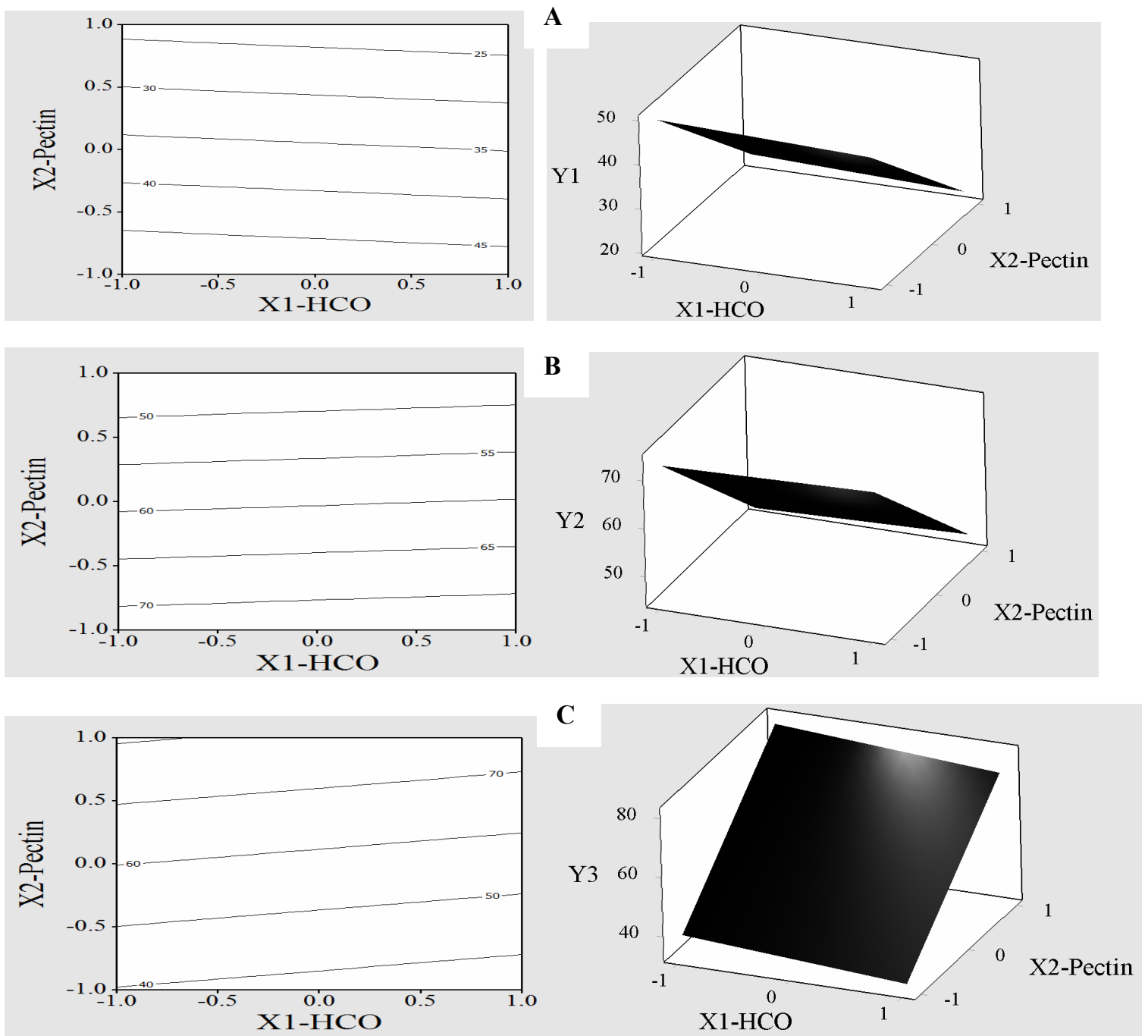

Fig 3: Response surface and contour plots for drug release after (A) 2 h (Y1); (B) 24 h (Y2); and (C) for time required for $25 \%$ drug release (Y3)

\section{DISCUSSION}

The slower release from the solid dispersion matrices using $\mathrm{HCO}$ alone can be due to almost complete coating of the IDM particles by HCO melted in the process of hot fusion. Further batches were prepared using combinations of $\mathrm{HCO}$ and PEC to check the synergistic effect of various combinations on the drug release.

On this preliminary study a factorial design was employed to find out the best combination of $\mathrm{HCO}$ and PEC that minimizes the further drug release in upper GIT and upon arrival to colon that releases the drug as quickly as possible.

\section{In vitro drug release}

It was expected that the penetration of the dissolution medium into the matrix will be low and hence, the release of the drug occurs at a slower rate. So, as the concentration of $\mathrm{HCO}$ increased the thickness of the drug particles coating increased leading to higher extent in drug release retardation.

From Fig. 3 it was concluded that at higher percentage of PEC, the tablets could remain intact in the physiological environment of stomach and small intestine but once tablets enter into the colon, it is acted upon by polysaccharidases, which degrade the PEC and hence promote release the drug in the colon.

The two criteria upon which the optimized formulations for colon delivery were selected are the percentage zero release in acidic medium $(\mathrm{pH} 1.2)$ and the slow release of the drug in $\mathrm{pH}$ 6.8. Formulations $F 7, F 8$ and $F 9$ fulfilled the previous two requirements. The slow release in vitro indicated reasonable release in vivo in presence of the pectinase enzyme. It was reported that the drug release in presence of rate cecal content could be increased from $20-30 \%$ 
[20]. Consequently that $100 \%$ drug release rate could be attained within $16 \mathrm{~h}$, which is the normal residence time of a solid dosage form in the colon [21]. Therefore, it can be concluded that F7, F8 and F9 matrix tablets (Fig. 2C) would be considered as promising sustained release formulations of IDM for colon delivery. Higuchi's kinetics explains why the drug diffuses at a comparatively slower rate $(0.043$ for $\mathrm{F} 4$ and 0.083 for F6) as the distance for diffusion increases. All the formulations showed slope (n) values ranging from 0.494 for $\mathrm{F} 4$ to 0.618 for F6. The $\mathrm{n}$ values for all formulations indicated nonFickian diffusion which refers to a combination of both diffusion and erosion controlled-drug release.

Traditionally, pharmaceutical formulators develop various formulations by changing one variable at a time but the method is time-consuming. However, many experiments not succeed in their purpose because they are not properly thought out and designed, and even the best data analysis cannot compensate lack of planning. Therefore, it is essential to understand the influence of formulation variables on the quality of formulations with a minimal number of experimental trials and subsequent selection of formulation variables to develop an optimized formulation using established statistical tools for optimization [22].

In case of $\mathrm{Y} 1$, the results of multiple regression analysis showed that both the coefficients $b_{1}$ and $b_{2}$ (coefficient of factors $X_{1}$ and $X_{2}$, respectively) bear a negative sign indicating a release retarding effect. It was anticipated that both matrix forming polymers would have synergistic retardant effect. The highly hydrophobic $\mathrm{HCO}$ and the gel forming polymer PEC ensured the expectation of very slow drug release rate. So increasing the amount of the two polymers in the formulation decreased the amount of drug released into the dissolution media. Depending on the value of the coefficient of factors, it can be stated that both polymers $\left(X_{1}\right.$ and $\left.X_{2}\right)$ were responsible for the obtained value of $Y_{1}$ but $X_{2}$ has more pronounced effect on drug release retardation.

The amount of drug released after $24 \mathrm{~h}$ is an important parameter for prominent drug release from sustained release matrix formulation. The data of the factorial equation for $Y 2$ showed that the coefficient factor of $X_{2}$ is negative indicating a release retarding effect. The delay in drug release may be conditioned by the proportion of PEC in the formulations. As shown in Fig 2, as the amount of PEC increased in the tablet matrices, the drug release was decreased after $24 \mathrm{~h}$.

The time required for $25 \%$ drug release was selected for comparison between the different formulations. The coefficient factor of $X_{1}$ is negative indicating that $\mathrm{Y} 3$ was strongly dependent on $\mathrm{HCO}$ as a matrix forming material. The time needed for melting of the hydrophobic polymer was the primary factor affecting the initial drug release.

Response surface methodology is a widely proficient approach in the development and optimization of drug delivery devices $[23,24]$. The three-dimensional response surface plot is very useful in learning about the main and interaction effects of the independent variables (factors), whereas two-dimensional contour plot gives a visual representation of values of the response $[23,24]$.

From the response surface analysis, it was found that the values decreased with the increase of two independent variables (amount of $\mathrm{HCO}$ and $P E C)$. The higher viscosity due to increasing amount of hydrophilic polymer used, PEC may promote the formation of highly viscous gel upon contact with aqueous fluids of the dissolution medium, which would retard the drug release rate from these IDM matrix tablets.

\section{CONCLUSION}

Indomethacin matrix tablets for colon delivery containing a combination of the polymers, $\mathrm{HCO}$ and PEC, hold good promise for drug release retardation. Successful $3^{2}$ full factorial design, development, and optimization of IDM tablets has been achieved in this study.

\section{ACKNOWLEDGEMENT}

This research project was supported by a grant from the Research Center of the Female Scientific and Medical Colleges, Deanship of Scientific Research, King Saud University.

\section{REFERENCES}

1. Yang L, Chu JS, Fix JA. Colon-specific drug delivery: new approaches and in vitro/in vivo evaluation. Int $J$ Pharm 2002; 235: 1-15.

2. Philip AK, Philip B. Colon targeted drug delivery systems: a review on primary and novel approaches. Oman Med J 2010; 25: 79-87.

3. Vinaykumar K, Sivakumar T, Tamizhmani T, Rajan TS, Chandran IS. Colon targeting drug delivery system: A 
review on recent approaches. Int J Pharm 2011; 2: 11-19.

4. Shukla S, Jain D, Verma K, Verma S. Formulation and in vitro characterization of alginate microspheres loaded with diloxanide furoate for colon-specific drug delivery. Asian J Pharm 2010; 4: 199-204.

5. Kumar DV, Mishra A, Easwari T. Formulation and Development of Acrycoat-Coated Chitosan Beads of Ornidazole for Colon Targeting. Eur J Appl Sci 2013; 5: 47-52.

6. Gawde P. Development of Mucoadhesive Microsphere for Colon Delivery. Int J Pharm \& Biol Arch 2012; 3. 440-442.

7. Varshosaz J, Emami J, Tavakoli N, Minaiyan M, Rahmani N, Dorkoosh F, Mahzoni P. Pectin Film Coated Pellets for Colon-targeted Delivery of Budesonide: Invitro/In-vivo Evaluation in Induced Ulcerative Colitis in Rat. Iran J Pharm Res 2012; 11: 733-745.

8. Kumar R, Patil M, Patil SR, Paschapur MS. Polysaccharides Based Colon Specific Drug delivery: A Review. Int Pharm Tech Res 2009; 1: 334-346.

9. Gallo O, Franchi A, Magnelli L, Sardi I, Vannacci A, Boddi $V$, et al. Cyclooxygenase-2 pathway correlates with VEGF expression in head and neck cancer. Implications for tumor angiogenesis and metastasis. Neoplasia 2001; 3: 53-61.

10. Guo YC, Chang CM, Hsu WL, Chiu SJ, Tsai YT, Chou $\mathrm{YH}$, et al. Indomethacin inhibits cancer cell migration via attenuation of cellular calcium mobilization. Molecules 2013; 18: 6584-6596.

11. Rayburn ER, Ezell SJ, Zhang R. Anti-inflammatory agents for cancer therapy. Mol cell pharmacol 2009, 1: 29-43.

12. Higuchi K, Umegaki E, Watanabe T, Yoda Y, Morita E, Murano $M$, et al. Present status and strategy of NSAIDs-induced small bowel injury. J gastroenterol 2009; 44: 879-888.

13. Hawkins C, Hanks GW. The gastroduodenal toxicity of nonsteroidal anti-inflammatory drugs: a review of the literature. J Pain Symptom Manage 2000; 20: 140 151.

14. Dupeyrón D, Kawakami M, Ferreira AM, Cáceres-Vélez $P R$, Rieumont J, Azevedo RB, et al. Design of indomethacin-loaded nanoparticles: effect of polymer matrix and surfactant. Int J Nanomedicine 2013; 8: 3467-3477.

15. Dash S, Murthy PN, Nath L, Chowdhury $P$. Kinetic modeling on drug release from controlled drug delivery systems. Acta Pol Pharm 2010; 67: 217-223.

16. Siepmann J, Peppas NA. Higuchi equation: derivation, applications, use and misuse. Int J Pharm 2011; 418: 6-12.

17. Higuchi T. Mechanism of Sustained-Action Medication. Theoretical Analysis of Rate of Release of Solid Drugs Dispersed in Solid Matrices. J Pharm Sci 1963; 52: 1145-1149.

18. Korsmeyer RW, Gurny R, Doelker E, Buri P, Peppas NA. Mechanisms of solute release from porous hydrophilic polymers. Int J Pharm 1983; 15: 25-35.

19. Basavoju S, Bostrom D, Velaga SP. Indomethacinsaccharin cocrystal: design, synthesis and preliminary pharmaceutical characterization. Pharm Res 2008; 25: 530-541.

20. Singhal $A$, Jain $H$, Singhal V, Elias EJ, Showkat A. Colontargeted quercetin delivery using natural polymer to enhance its bioavailability. Pharmacognosy Res 2011; 3: 35-39.

21. Prasath $B A$, Sankaranand $R$, Nantheeswaran $S$, Swetha $T$, Anoosha $M$, Sunitha $P$, et al. Colon targeted drug delivery of propranolol hydrochloride by using different natural polymers. Int J Res Pharm Sci 2011; 2: 353-358.

22. Chaudhary H, Patel B, Patel D, Patel C. Optimization of Theophylline sustained release tablets using 32 full factorial design and response surface analysis. Indian J Novel Drug deliv 2012; 4: 163-171.

23. Malakar J, Nayak AK, Pal D. Development of cloxacillin loaded multiple-unit alginate-based floating system by emulsion-gelation method. Int J biol macromol 2012; 50:138-147.

24. Nayak AK, Pal D. Development of $\mathrm{pH}$-sensitive tamarind seed polysaccharide-alginate composite beads for controlled diclofenac sodium delivery using response surface methodology. Int J biol macromol 2011; 49:784-793. 